\title{
SARS-CoV-2 Neutralization in Convalescent Plasma and Commercial Lots of Plasma-Derived Immunoglobulin
}

\author{
Andreas Volk ${ }^{1} \cdot$ Caroline Covini-Souris $^{2} \cdot$ Denis Kuehnel ${ }^{1} \cdot$ Christian De Mey $^{3} \cdot$ Jürgen Römisch $^{2} \cdot$ Torben Schmidt $^{1}$
}

Accepted: 10 November 2021 / Published online: 29 November 2021

(c) The Author(s) 2021

\begin{abstract}
Introduction Patients with primary or secondary immunodeficiency (PID or SID) face increased insecurity and discomfort in the light of the COVID-19 pandemic, not knowing if and to what extent their comorbidities may impact the course of a potential SARS-CoV-2 infection. Furthermore, recently available vaccination options might not be amenable or effective for all patients in this heterogeneous population. Therefore, these patients often rely on passive immunization with plasmaderived, intravenous or subcutaneous immunoglobulin (IVIG/SCIG).

Whether the ongoing COVID-19 pandemic and/or the progress in vaccination programs lead to increased and potentially protective titers in plasma-derived immunoglobulins (Ig) indicated (e.g., for humoral immunodeficiency) remains a pressing question for this patient population.

Purpose We investigated SARS-CoV-2 reactivity of US plasma-derived IVIG/SCIG products from the end of 2020 until June 2021 as well as in convalescent plasma (CP) from May 2020 to August 2020 to determine whether potentially neutralizing antibody titers may be present.

Methods Final containers of IVIG/SCIG and CP donations were analyzed by commercial ELISA for anti-SARS-CoV-2 S1-receptor binding domain (RBD) IgG as well as microneutralization assay using a patient-derived SARS-CoV-2 (D614G) isolate. Neutralization capacities of 313 single plasma donations and 119 plasma-derived IVIG/SCIG lots were determined. Results obtained from both analytical methods were normalized against the WHO International Standard. Finally, based on dense pharmacokinetic profiles of an IVIG preparation from previously published investigations, possible steady-state plasma levels of SARS-CoV-2 neutralization capacities were approximated based on currently measured anti-SARS-CoV-2 potencies in IVIG/SCIG preparations.

Results CP donations presented with high variability with regards to anti-SARS-CoV-2 reactivity in ELISA as well as in neutralization testing. While approximately $50 \%$ of convalescent donations were not/low neutralizing, approximately $10 \%$ were at or above $600 \mathrm{IU} / \mathrm{mL}$. IVIG/SCIG lots derived from pre-pandemic plasma donations did not show neutralizing capacities for SARS-CoV-2. Lots produced between December 2020 and June 2021 entailing plasma donations after the emergence of SARS-CoV-2 showed a rapid and constant increase in anti-SARS-CoV-2 reactivity and neutralization capacity over time. While lot-to-lot variability was substantial, neutralization capacity increased from a mean of $21 \mathrm{IU} / \mathrm{mL}$ in December 2020 to $506 \mathrm{IU} / \mathrm{mL}$ in June 2021 with a maximum of $864 \mathrm{IU} / \mathrm{mL}$ for the most recent lots. Pharmacokinetic extrapolations, based on non-compartmental superposition principles using steady-state reference profiles from previously published pharmacokinetic investigations on IVIG in PID, yielded potential steady-state trough plasma levels of $16 \mathrm{IU} / \mathrm{mL}$ of neutralizing SARS-CoV-2 IgG based on the average final container concentration from May 2021 of $216 \mathrm{IU} / \mathrm{mL}$. Maximum extrapolated trough levels could reach $64 \mathrm{IU} / \mathrm{mL}$ based on the latest maximal final container potency tested in June 2021.

Conclusions SARS-CoV-2 reactivity and neutralization capacity in IVIG/SCIG produced from US plasma rapidly and in part exponentially increased in the first half of 2021. The observed increase of final container potencies is likely trailing the serological status of the US donor population in terms of COVID-19 convalescence and vaccination by at least 5 months due to production lead times and should in principle continue at least until Fall 2021. In summary, the data support rapidly
\end{abstract}

Andreas Volk, Caroline Covini-Souris have contributed equally.

Jürgen Römisch, Torben Schmidt have contributed equally.

Extended author information available on the last page of the article 
increasing levels of anti-SARS-CoV-2 antibodies in IVIG/SCIG products, implicating that a certain level of protection could be possible against COVID-19 for regularly substituted PID/SID patients. Nevertheless, more research is still needed to confirm which plasma levels are needed to provide protection against SARS-CoV-2 infection in immune-compromised patients.

\section{Plain Language Summary}

People with deficiencies in their immune system often have an insufficient antibody response to antigens such as bacteria, viruses, or vaccines. These patients therefore often receive antibodies from healthy people to replace the missing antibodies and build a first line of defense against infections. These antibodies (also called immunoglobulins [Ig]) are prepared from plasma, the liquid fraction of the blood without cells, of healthy donors. This plasma is then split up during pharmaceutical production into its protein components. One of these is immunoglobulin $\mathrm{G}(\operatorname{IgG})$, which is the protein family that neutralizes/ inactivates infectious agents as well as marks these infectious agents so they can be recognized by other parts of the immune system. With the ongoing COVID-19 pandemic and the severe to fatal outcomes for certain patient groups, especially people with impaired immunity, these patients and their physicians are interested in whether their antibody replacement therapy also confers protection against SARS-CoV-2 infection. We analyzed the capability of plasma-derived Ig lots to (i) recognize SARS-CoV-2 protein by ELISA method as well as (ii) neutralize SARS-CoV-2 by neutralization studies using the actual virus under biosafety level 3 (BSL-3) conditions. Here we show increasing anti-SARS-CoV-2 activity over time of manufactured Ig lots produced between December 2020 and June 2021. The most recent lots had a neutralizing activity of up to 864 IU/ $\mathrm{mL}$. Considering that the US represents Octapharma's main plasma source, the progress in vaccination levels together with the evolution of the COVID-19 pandemic in this country suggests that the intravenous or subcutaneous immunoglobulin (IVIG/SCIG) neutralization capacities against SARS-CoV-2 might still increase and could potentially reach a level where antibody plasma concentrations in the patient confer immune protection.

\section{Key Points}

Patients with humoral immunodeficiency rely on plasmaderived immunoglobulin for passive immunization against numerous pathogens.

SARS-CoV-2 neutralization capacities of plasma-derived immunoglobulins have increased over time with the ongoing COVID-19 pandemic and vaccination campaigns.

Plasma-derived immunoglobulin in prophylactic use for immunodeficient patients could potentially protect against SARS-CoV-2 infection in the future.

\section{Introduction}

The principle of passive immunization, that is, the infusion of antibodies from a healthy immunized or convalescent donor to patients not mounting their own active immune response, is a long-standing treatment option for infectious diseases and was first applied by Emil von Behring, who received the first ever Nobel prize in 1901 for serum therapy of diphtheria [1]. Passive immunization refers to antibody transfer by means of recombinant monoclonal antibody, plasma-derived intravenous or subcutaneous immunoglobulin (IVIG/SCIG), or convalescent plasma (CP). In fact, $\mathrm{CP}$ therapy has faced a renaissance as a possible treatment option in the currently ongoing COVID-19 pandemic to bridge the period until therapeutics, and especially vaccines as protective measures, became available [2-4]. The US Food and Drug Administration (FDA) granted emergency use authorization for CP therapy in August 2020 and revised this guidance in March 2021 to use only higher titer $\mathrm{CP}$ early in the course of the disease [5]. However, for the therapeutic setting, a meta-analysis by Peng et al. identified a total of 243 published studies including 64 clinical trials on CP administration for prevention and treatment of COVID-19 by April 2021 [6]. In summary, the efficacy of CP therapy against COVID-19 has not been unequivocally shown and remains a matter of debate and further clinical investigation [7-12]. The criticality of early treatment with $\mathrm{CP}$ as well as the required dose and specific antibody titers of the donations have been discussed as part of relevant drivers for treatment success [11]. Likewise, the prophylactic use of CP has not found broad application [6]. However, efficacious prophylaxis against disease using $\mathrm{CP}$ has been shown in hamster and macaque models [13-15]. Furthermore, clinical efficacy has been shown with recombinant monoclonal antibody prophylaxis supporting the notion that immunoglobulin $\mathrm{G}$ (IgG) molecules can prevent infection/ COVID-19 [16, 17].

Active immunization of patients with primary immunodeficiencies (PID) as well as secondary immunodeficiencies 
(SID), which in part manifest as impeded or a complete lack of humoral response, has recently been reported with encouraging findings $[18,19]$. However, not all patients within this heterogeneous group are amenable to vaccination or vaccination might not lead to immune protection [20,21]. Furthermore, COVID-19 disease in this indication group has been reported to have both less [22] and more severe outcomes depending on comorbidities and individual patient factors [23].

Regardless of the amenability of active vaccination and the potential disease outcome, passive immunization by repeated injection of IVIG/SCIG for at least a part of this patient group is the standard of care for humoral deficiency and has been ongoing prior to and throughout the COVID19 pandemic [24-26]. IVIG/SCIG are purified and concentrated immunoglobulin (Ig) preparations derived from pooled plasma donations [27, 28]. Therefore, the reactivity and neutralizing potency of these IgG pharmaceutical products are directly dependent on the epidemiologic experience of the donor population [19-21].

It is thus of high interest how currently manufactured IVIG/SCIG can serve these immunodeficient patient groups in terms of protection against a SARS-CoV-2 infection or impeding disease severity of COVID-19. First reports of anti-SARS-CoV-2 reactivity and neutralization capacities in commercially produced immunoglobulins have already been published [29-33].

To obtain an impression on how $\mathrm{CP}$ donations vary in terms of potency, we first investigated a selection of COVID19 CP donations from May 2020 to August 2020 for SARSCoV-2 reactivity using commercially available anti-SARSCoV-2 IgG ELISA and an inhouse established SARS-CoV-2 microneutralization assay under biosafety level 3 (BSL-3) conditions to assess the actual neutralization capacity.

Furthermore, we analyzed commercial lots of immunoglobulin manufactured from November 2020 to June 2021 by ELISA. A fraction of these lots was subsequently subjected to neutralization testing against actual SARS-CoV-2 virus.

Lastly, we performed calculations based on previous pharmacokinetic profiles of IVIG [34] to obtain a first and preliminary insight into possibly achievable steady-state plasma levels of anti-SARS-CoV-2 IgG in patients regularly dosed with IVIG.

\section{Material and Methods}

\subsection{Single Donation of Convalescent Plasma}

Analyzed CP donations were collected from May 2020 to August 2020. Octapharma invited donors to present proof of resolved SARS-CoV-2 infection (either by positive diagnostic test or positive serological test) to be eligible to donate $\mathrm{CP}$ after a deferral period of 14 days after either diagnostic test or symptom cessation, as applicable.

\subsection{IVIG/SCIG}

Octagam $^{\circledR}$ and Panzyga ${ }^{\circledR}$ are polyclonal IVIG and Cutaquig ${ }^{\circledR}$ is a polyclonal SCIG product derived from thousands of plasma donations. We tested lots derived from US donations prepared from November 2020 to June 2021. Octagam ${ }^{\circledR}$ is available as $50-\mathrm{mg} / \mathrm{mL}$ and $100-\mathrm{mg} / \mathrm{mL}$ ( $5 \%$ and $10 \%$ ) preparations, Cutaquig ${ }^{\circledR}$ is available as $165-\mathrm{mg} / \mathrm{mL}(16.5 \%)$ while Panzyga ${ }^{\circledR}$ is available as $100-\mathrm{mg} / \mathrm{mL}(10 \%) \mathrm{IgG}$ preparations. All reported results were normalized to a potency of $100 \mathrm{mg} \mathrm{IgG/mL}$ to remove bias from different formulations.

\subsection{Anti-SARS-CoV-2 IgG ELISA Kit}

The following ELISA kits were used for detection of antiSARS-CoV-2 IgG against receptor binding domain (RBD) of spike protein S1: EI-2606-9601 G ELISA kit (EUROIMMUN Medizinische Labordiagnostika AG, Lübeck, Germany) for qualitative detection; QuantiVac EI-2606-9601-G ELISA (EUROIMMUN Medizinische Labordiagnostika AG, Lübeck, Germany) for quantitative determination of $\operatorname{IgG}$ titers. Tests were performed as instructed by the provider.

$\mathrm{CP}$ was stored frozen and thawed promptly before analysis. Samples were diluted with buffer solutions provided in each ELISA kit. After qualitative detection, results were expressed as antibody ratio.

IVIG/SCIG lots were diluted using buffer solutions included in each ELISA kit. IgG 5\%, 10\%, and 16.5\% preparations were tested in three dilution series ranging from $1: 1$ to $1: 10$. All samples were tested in octuplicates. Results were obtained in relative units $(\mathrm{RU} / \mathrm{mL})$ and were normalized against the First WHO International Standard in binding antibody units $/ \mathrm{mL}(\mathrm{BAU} / \mathrm{mL})$ as described by the test kit provider. All quantitative results were normalized to $100 \mathrm{mg} /$ $\mathrm{mL}$ IgG.

\subsection{Cell Culture}

Vero cells (CCL-81, American Type Culture Collection) were cultured in Roswell Park Memorial Institute (RPMI)1640 medium, supplemented with $10 \%$ fetal bovine serum and $1 \%$ penicillin/streptomycin at $37{ }^{\circ} \mathrm{C}, 5 \% \mathrm{CO}_{2}$ in saturated humidity.

FRhK-4 cells (CRL-1688, American Type Culture Collection) were cultured in Eagle's minimal essential medium (EMEM) supplemented with 14\% RPMI-1640, 5\% fetal 
bovine serum and $1 \%$ penicillin/streptomycin at $37{ }^{\circ} \mathrm{C}, 5 \%$ $\mathrm{CO}_{2}$ in saturated humidity.

\subsection{Virus}

SARS-CoV-2 D614G (Human 2019-nCoV ex China BavPat1/2020_Germany ex China, GISAID ID: EPI_ ISL_406862) was kindly provided by Prof. Dr Christian Drosten, Institute of Virology, Charité, Universitätsmedizin Berlin, Germany [35].

All handling of virus was performed under BSL- 3 conditions according to German law.

The virus was propagated on FRhK-4 cells established with $20 \mathrm{~mL}$ of $21.5 \times 10^{3}$ cells $/ \mathrm{mL}$ in FRhK-4 culture medium (see above) in a T75 cell culture flask. Three days later, the culture medium was removed and the culture was inoculated with SARS-CoV-2 at a multiplicity of infection of $0.01 \mathrm{in} 5-\mathrm{mL}$ virus suspension and kept for $1 \mathrm{~h}$ at $37^{\circ} \mathrm{C}$, $5 \% \mathrm{CO}_{2}$ in saturated humidity. Inoculum was removed and the cells were washed once with phosphate-buffered saline. After addition of $30 \mathrm{~mL}$ FRhK-4 culture medium, cells were maintained for 4 days. Subsequently, the medium was exchanged to FRhK-4 medium without fetal bovine serum. On day 6 after inoculation, virus-containing supernatant was removed and centrifuged to remove cells and cellular debris $\left(4{ }^{\circ} \mathrm{C}, 15 \mathrm{~min}\right.$ at $\left.1500 \times g\right)$. The supernatant was kept refrigerated during cell lysis steps. The culture flask and the centrifugal pellet were frozen three times in a $-80{ }^{\circ} \mathrm{C}$ freezer for cell lysis. The flask was rinsed with $5 \mathrm{~mL}$ of the refrigerated virus-containing supernatant and subsequently used to resuspend the freeze-thawed centrifugal pellet. After repeated centrifugation of the cell lysate suspension, the supernatant was added to the remainder refrigerated virus suspension followed by $0.45 \mu \mathrm{m}$ filtration. After aliquoting, the virus was stored in a $-80{ }^{\circ} \mathrm{C}$ freezer until use.

\subsection{Standards and Reagents}

\subsubsection{Neutralization Standards}

WHO International Standard/First WHO International Standard for anti-SARS-CoV-2 immunoglobulin (human) was obtained from the National Institute for Biological Standards and Control (NIBSC), Potters Bar, Hertfordshire, UK (NIBSC code: 20/136) [36].

The internal neutralization standard ' $V$ ' was generated in-house at Octapharma Virus and Prion Validation by pooling a selection of $\mathrm{CP}$ samples. After pooling, samples were aliquoted and kept frozen at $-80{ }^{\circ} \mathrm{C}$ until use. Standard was diluted 1:40 initial dilution in 20\% citrate dextrose (ACD, Sigma ${ }^{\circledR}$ ) in Vero culture medium to avoid clotting. The calibrated potency of internal standard ' $\mathrm{V}$ ' was $1439 \mathrm{IU} / \mathrm{mL}$.
The internal neutralization standard ' $\mathrm{O}$ ' was a high-titer, single-source plasma donation obtained from Octapharma Plasma Inc., Charlotte, NC, USA. After thawing, the donation was aliquoted and kept frozen at $-80{ }^{\circ} \mathrm{C}$ until use. Standard was diluted 1:40 initial dilution in 20\% ACD in Vero culture medium to avoid clotting. The calibrated potency of internal standard 'O' was $2017 \mathrm{IU} / \mathrm{mL}$.

\subsection{Neutralization Testing}

Neutralization testing (NT) was done in two microneutralization assay formats. Both assays were not prospectively validated. In both, Vero cultures were prepared one day prior to assay conduct and $120 \mu \mathrm{L}$ was seeded in each of the 96 wells with $0.5 \times 10^{4}$ cells $/ \mathrm{mL}$ ( 600 cells per well).

In the screening assay format, which was used in the $\mathrm{CP}$ donation testing, each plasma sample was thawed at $37{ }^{\circ} \mathrm{C}$ and initially diluted 1:40 with $20 \%$ ACD in cell culture medium to avoid clotting. Subsequently, samples were serially diluted 1:2-fold in six consecutive steps. Each of the four parallel dilutions was assayed once for neutralization. The assay principle was adapted from Gauger \& Vincent [37].

In the potency assay format deployed for final container testing, each sample was assayed in three independent dilution series [30,38]. After an initial 1:10 dilution step, ten consecutive 1:2 dilution steps were performed. Each dilution was assayed in octuplicates, respectively. Experimental performance of both screening and potency assay formats are summarized in Supp. Fig. 1 in the electronic supplementary material (ESM).

In both assay versions, each sample dilution was subsequently challenged with an equal volume of SARS-CoV-2 suspension, which had a titer of $3.0 \log _{10} 50 \%$ tissue culture infectious dose $\left(\mathrm{TCID}_{50}\right) / \mathrm{mL}$. The virus titer was confirmed in each experiment run by so-called back titrations (refer to Sect. 2.8 'Virus Titration'). A mean titer of $n=5$ titrations was determined to accurately account for the actual viral load in the immune neutralization, which was used as a normalizing factor to account for potential inter-run variances.

In both formats, the neutralization reaction was incubated for $150 \pm 15 \mathrm{~min}$ at $37^{\circ} \mathrm{C}$ in a $\mathrm{CO}_{2}$ incubator at saturated humidity. After the incubation period, $100 \mu \mathrm{L}$ of each replicate dilution was transferred onto a 96-well culture of Vero cells (see above). Inoculated cultures were maintained for 7 days at $37{ }^{\circ} \mathrm{C}, 5 \% \mathrm{CO}_{2}$ in saturated humidity. On day 7 , cultures were microscopically evaluated for the presence or absence of cytopathic effect by two independent operators (four-eyes principle). Neutralization potency by means of dilution to achieve a $50 \%$ neutralization of virus was calculated using SpearmanKärber-based statistics [38]. 
To convert the identified NC50 dilution values into international units, the normalized (mean) neutralization values of the sample were divided by the (mean) neutralization of the internal standard ' $\mathrm{V}$ ' or ' $\mathrm{O}$ ' run along the same experiment and then multiplied by the calibrated potency of the respective internal standards in international units.

\subsection{Virus Titration}

Serial 1:3 dilutions of the virus stock were prepared in 12 consecutive steps in Vero cell culture medium. Subsequently, $8 \times 100 \mu \mathrm{L}$ of each dilution were added to a 96-well plate containing Vero cultures established one day earlier as described above. Inoculated cultures were maintained for 7 days at $37{ }^{\circ} \mathrm{C}, 5 \% \mathrm{CO}_{2}$ in saturated humidity. On day 7 , cultures were microscopically evaluated for the presence or absence of cytopathic effect by two independent operators. Viral titer was calculated using Spearman-Kärber statistics [39].

\subsection{Pharmacokinetic Analysis}

Steady-state levels of SARS-CoV-2-neutralizing IgG on 4-weekly dosing were approximated by superposition principles using baseline-adjusted, dose-normalized reference profiles from a previously published clinical trial (EudraCT 2009-011434-10) that investigated the steady-state pharmacokinetics of IgG on 4-weekly repeated dosing of IVIG $10 \%$ in patients with PID [34]. The individual courses of total IgG were baseline-adjusted, assuming that the baseline levels were residuals from previous dosing whilst endogenous levels were negligible. To be able to pool the profiles across subjects, the baseline-adjusted profiles were dose-normalized. The time courses of the median, 25th (P25), and 75th (P75) percentile levels of the baseline-adjusted dose-normalized data were used as reference profiles. These reference profiles were expanded by linear/log-linear interpolation between sampling points and extrapolation beyond the last quantifiable value by means of the apparent terminal disposition rate constant. Steady-state levels were approximated by building time-staggered superposition cascades of the reference profiles for ten 4-weekly doses, assuming the pharmacokinetics to be dose-proportional and time-invariant.

\subsection{Statistical Methods}

All statistical methods are identified in the respective figure legends. For statistical analyses, the software GraphPad Prism version 8.4.3 (686) for Windows (GraphPad Software, San Diego, California, USA; www.graphpad.com), was used.
Pharmacokinetic analyses were carried out by means of PCModfit v7.0 (2021; Copyright of Graham D. Allen; available at https://pcmodfit.co.uk/index.html, accessed on 23 July 2021).

The minimal serorelevant exposure in percentage of the US population (as depicted in Fig. 2b) was calculated by data obtained from CDC Covid Tracker [40]: sum of "Cumulative Count of People Receiving at Least One Dose Reported to CDC by Date Administered, United States" (https://covid. cdc.gov/covid-data-tracker/\#vaccination-trends_vacctrendsonedose-cum, accessed on 12 July 2021) and the "Trends in Total [cumulative] Cases in The United States Reported to CDC" (https://covid.cdc.gov/covid-data-tracker/\#trends_ totalcasescumulative, accessed on 12 July 2021) divided by the total US population [41].

\section{Results}

We obtained CP donation units from Octapharma Plasma's donation centers in the US between May 2020 and August 2020 to understand early in the pandemic how CP donations present themselves in terms of titer and inter-donation variation. We therefore first tested 133 single donations by means of qualitative anti-SARS-CoV-2-S1 RBD IgG ELISA. We found a positive signal of anti-SARS-CoV-2 IgG in $79 \%$ of $\mathrm{CP}$ donations, while $15 \%$ and $6 \%$ of the donations exhibited borderline and negative results, respectively. The antibody ratio ranged from $<0.1$ (limit of detection, LOD) up to 16 while the mean \pm standard deviation (SD) ratio was $4.5 \pm$ 3.6 (Fig. 1a).

We next set out to investigate what these ELISA data mean in terms of actual virus neutralization. Therefore, 313 $\mathrm{CP}$ donations including the above sample set were analyzed by actual virus neutralization in a so-called NT screening assay format (Fig. 1b). We found a high variability of neutralization activity among CP donations. Twenty-five percent had a neutralization capacity close to or below the LOD (0-45 IU/mL); $28 \%$ had only a weak neutralization titer of $<150 \mathrm{IU} / \mathrm{mL} ; 21 \%$ of donations had a mean titer of $223 \mathrm{IU} / \mathrm{mL}$, representing a moderate/average neutralization; $16 \%$ had a neutralization titer between $300 \mathrm{IU} / \mathrm{mL}$ and $600 \mathrm{IU} / \mathrm{mL}$; while only $10 \%$ of all donations had a neutralizing activity of at least $600 \mathrm{IU} / \mathrm{mL}$. The maximal donation neutralization titer found was $2017 \mathrm{IU} / \mathrm{mL}$. The mean \pm SD neutralization titer of all convalescent donations was $245 \pm$ $302 \mathrm{IU} / \mathrm{mL}$.

Given the reports on frequent asymptomatic to mild COVID-19 infections and the general interest in how epidemiologic developments (infection as well as vaccination programs) in the US donor population is reflected in IVIG/ SCIG, we investigated commercial lots derived from US 
a

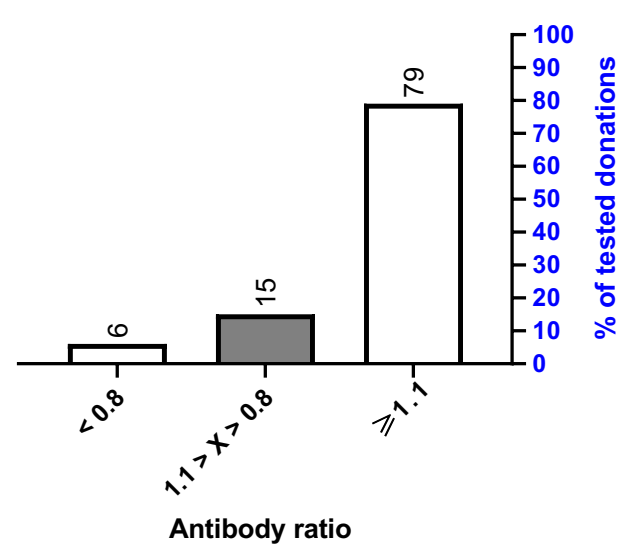

Fig. 1 Characterization of CP single donations for anti-SARS-CoV-2 reactivity by means of $\mathbf{a}$ IgG ELISA and $\mathbf{b}$ microneutralization assay. a ELISA ratios of anti-SARS-CoV-2 IgG are plotted. Cut-off is set by ELISA kit manufacturer as 1.1. Interpretation was negative if ratio is $<0.8$; positive if $\geq 1.1$; borderline if $1.1>x>0.8$. b Samples are clustered into neutralization potency (NC50) bins (right) and also shown as total sample set (left). For each ranked sub-population, the

plasma sources for SARS-CoV-2 reactivity from November 2020 until June 2021 by means of quantitative antiSARS-CoV-2 S1 RBD IgG ELISA (Fig. 2a). Pre-pandemic IVIG/SCIG lots all tested negative in the ELISA, excluding cross-reactivity of the assay against 'common cold' coronaviruses. Systematic investigations started in November 2020 and the first reactive lots were detected in December 2020 with ELISA IgG titers ranging from 40 to $170 \mathrm{BAU} / \mathrm{mL}$ with a mean value of $100 \mathrm{BAU} / \mathrm{mL}$. A progressive reactivity increase was observed, which took up pace in the very last months of observation. A mean \pm SD anti-SARS-CoV-2 IgG titer of $1048 \pm 363 \mathrm{BAU} / \mathrm{mL}$ was found in IVIG/SCIG lots produced in June 2021.

To substantiate this information, we further tested ELISApositive lots in NT in the potency assay format (Fig. 2b).

As was seen with the ELISA data, the first neutralizing IVIG/SCIG lots were identified in December 2020 (mean \pm SD neutralization titer of $21 \pm 15 \mathrm{IU} / \mathrm{mL}$ ). An exponential, yet slow increase in neutralization activities was subsequently observed (i.e., mean values \pm SD in February 2021: $61 \pm 37 \mathrm{IU} / \mathrm{mL}$; April 2021: $107 \pm 32 \mathrm{IU} / \mathrm{mL}$; May 2021: $216 \pm 96 \mathrm{IU} / \mathrm{mL}$; and June 2021: $506 \pm 242 \mathrm{IU} / \mathrm{mL}$ ). The maximum NC50 measured was $864 \mathrm{IU} / \mathrm{mL}$. We fitted the median SARS-CoV-2 neutralizing titers by exponential growth equation fit (least squares regression without weighing, no outlier handling and constraints) and found an $R^{2}$ of 0.98 .

For comparison and as a possible reference to the US plasma donor population, data adapted from CDC

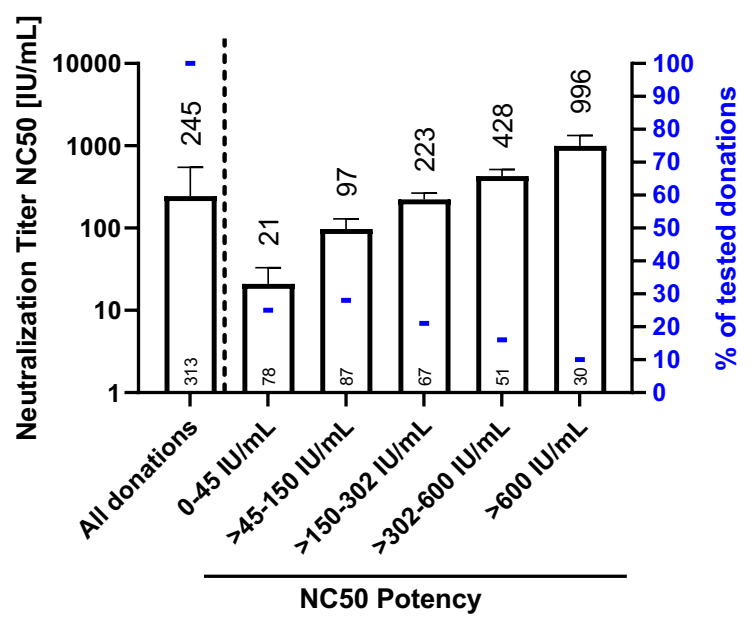

mean normalized neutralization titers \pm SD are depicted on the left $\mathrm{y}$-axis and values are shown above bars. The number of donations binned to each NC50 potency subset is shown at the bottom of each bar. The fraction of each subset to the total sample size is indicated by blue horizontal lines and depicted on the right $y$-axis. $C P$ convalescent plasma, IU international units, NC50 concentration at $50 \%$ neutralization, $S D$ standard deviation

epidemiologic surveillance on the relative minimal SARSCoV-2 exposure of the total US population [\%] is referenced in Fig. 2b [40].

We also performed correlation of the anti-SARS-CoV-2 IgG ELISA data and the NT results and found a correlation coefficient of $\mathrm{r}=0.94$ (Pearson, two-tailed, 95\% CI) with $p<0.0001$ indicating a quantitative character of this $\operatorname{IgG}$ ELISA. The linear regression $R^{2}$ was 0.89 (Fig. 2c).

Finally, we investigated how the currently measured final container potencies relate to steady-state plasma levels of anti-SARS-CoV-2 IgG in a patient receiving IVIG $10 \%$. We deployed data from a previously published trial (EudraCT 2009-011434-10) with pharmacokinetic characterization of the levels of total IgG on repeated 4-weekly IVIG dosing (median dose: $27.4 \mathrm{~g}$, inter-quartile range (IQR): 20.4-29.1) in 30 patients ( 11 females, 19 males; 8 children, 4 adolescents, and 18 adults) with PID (median body weight [BW]: $67.7 \mathrm{~kg}$, IQR: $52.4-75.3$ ) [34]. As detailed in the methods section, individual time courses of the untransformed $\mathrm{IgG}$ levels (Supp. Fig. 2a, see ESM) were baseline adjusted (Supp. Fig. 2b, see ESM) and subsequently normalized to the IVIG dose administered (Supp. Fig. 2c, see ESM). Ultimately, the normalized, baseline-adjusted one-dose pharmacokinetic profiles were expanded by staggered superposition to achieve an assumption of a pharmacokinetic time-course of a 4-weekly IVIG treatment regimen (Supp. Fig. 2d, see ESM). With the median dose of the original experiment, such approximations based on the median reference profile yield an average $\left(C_{a v}\right)$ level in steady-state of $9.6 \mathrm{mg} / \mathrm{mL}$ of 
a

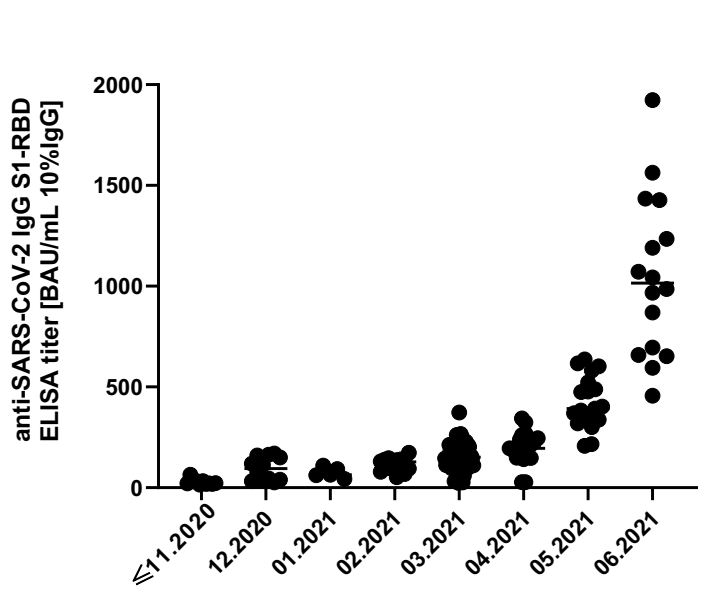

C

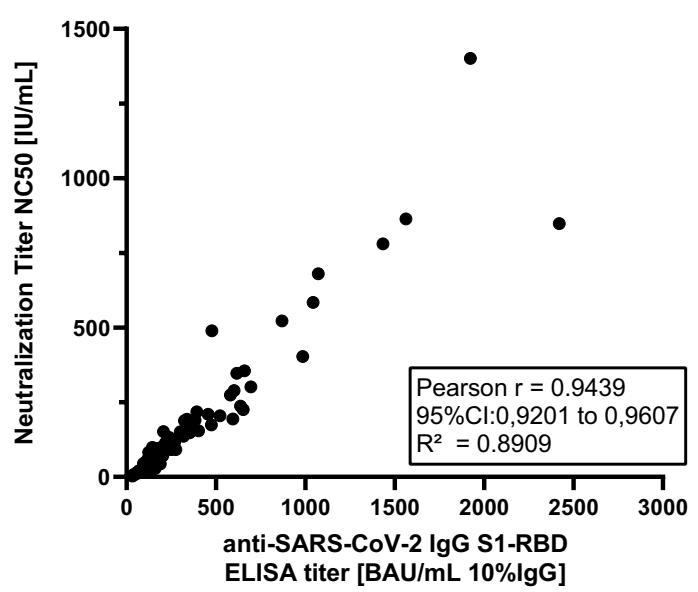

b

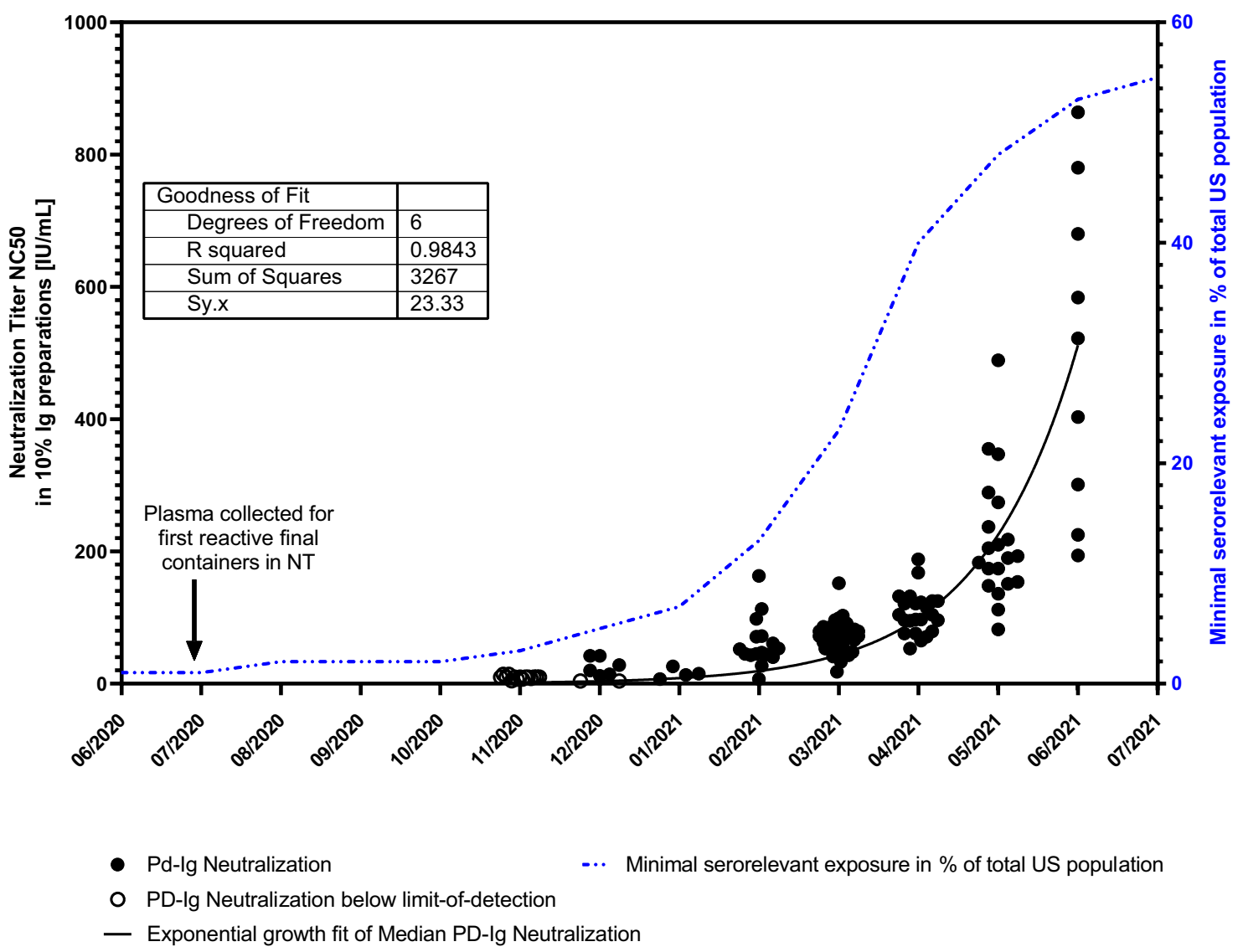

Fig. 2 SARS-CoV-2 reactivity and neutralization titer of IVIG/SCIG final containers from November 2020 to June 2021. a Scatter plot for reactivity of $10 \%$ IVIG/SCIG final containers normalized to $10 \%$ Ig in commercial IgG ELISA. Each dot represents the mean result of 8 determinations per sample counted as one measurement. The month of production is plotted against ELISA signal intensity, which was normalized against the WHO International Standard and to $10 \% \operatorname{IgG}(100 \mathrm{mg} / \mathrm{mL})$. b Neutralization titer of $10 \%$ IVIG/SCIG as determined by microneutralization assay is depicted on the left $y$-axis in IU/mL. Each dot represents the mean of triplicate analysis, counting as one measurement. Neutralization over time was fitted (solid line) using non-linear fit 'exponential growth equation' on the median values under GraphPad Prism version 8.4.3 (686). The cumulative minimal serologically relevant exposure of the total US population is depicted as a dash-dotted line (right $y$-axis) in blue. The latter were obtained from CDC Covid Data Tracker [40]. c Correlation analysis of ELISA ( $x$-axis) and microneutralization results ( $y$-axis). Correlation coefficient was calculated using two-tailed, Gaussian distributed values at 95\% CI (Pearson) under GraphPad Prism version 8.4.3 (686). BAU binding antibody units, $C I$ confidence interval, IVIG/ $S C I G$ intravenous or subcutaneous immunoglobulin 
total $\mathrm{IgG}$ surrounded by a fluctuation from a trough $\left(C_{\min }\right)$ of $7.4 \mathrm{mg} / \mathrm{mL}$ to a peak $\left(C_{\max }\right)$ of $14.8 \mathrm{mg} / \mathrm{mL}$. $C_{\text {av }}$ levels of reference profiles at the 25th and 75th percentile (P25 and P75) were 5.5 and $7.3 \mathrm{mg} / \mathrm{mL}$, respectively.

Next, we set out to transfer the measured SARS-CoV-2 neutralization potency in final containers to total IgG plasma levels-assuming no antibody-specific elimination process. We arbitrarily chose a recent, yet average, final container concentration to perform the superposition (i.e., May 2021: $216 \pm 96 \mathrm{IU} / \mathrm{mL}$ per $100 \mathrm{mg} / \mathrm{mL}$ ). The resulting potential titers in plasma of PID patients over the course of 10 superpositioned dosings is shown in Fig. 3. With a neutralization potency of $\sim 2 \mathrm{IU} / \mathrm{mg}$, dosing of the original study (i.e., 4-weekly doses of $0.406 \mathrm{~g} / \mathrm{kg}$ ) could be approximated to yield an average steady-state level of SARS-CoV-2 neutralizing $\operatorname{IgG}\left(C_{\mathrm{av}}\right)$ of $20 \mathrm{IU} / \mathrm{mL}\left(C_{\min }: 16 \mathrm{IU} / \mathrm{mL} ; C_{\max }: 32 \mathrm{IU} /\right.$ $\mathrm{mL}$ ) (Table 1). For the same dosage but using the P25 reference profile, $C_{\mathrm{av}}$ in steady-state would be $15 \mathrm{IU} / \mathrm{mL}\left(C_{\min }\right.$ : $11 \mathrm{IU} / \mathrm{mL} ; C_{\max }: 25 \mathrm{IU} / \mathrm{mL}$ ) and be $22 \mathrm{IU} / \mathrm{mL}$ for the P75 reference profile $\left(C_{\min }: 16 \mathrm{IU} / \mathrm{mL} ; C_{\max }: 37 \mathrm{IU} / \mathrm{mL}\right)$.

\section{Discussion}

Immunodeficient patients may not have an efficient response to vaccination and therefore rely on prophylaxis measures not only against SARS-CoV-2 infection but also other circulating pathogens. Plasma-derived Ig is the standard of care to substitute the antibody repertoire in these patients with IVIG/SCIG manufactured from thousands of donations per batch. In light of the pandemic, these immunodeficient patients and their health care professionals are interested in if and when a potential
Table 1 Approximated steady-state trough $\left(C_{\min }\right)$, peak $\left(C_{\max }\right)$, and average $\left(C_{\mathrm{av}}\right)$ neutralizing SARS-CoV-2 IgG levels estimated through a superposition cascade with time-staggered dosing using the median, 25th (P25), and 75th (P75) percentile baseline-adjusted and dose-normalized reference curves

\begin{tabular}{llll}
\hline & $\begin{array}{l}\text { Derived from } \\
\text { the median ref- } \\
\text { erence profile }\end{array}$ & $\begin{array}{l}\text { Derived from } \\
\text { the P25 refer- } \\
\text { ence profile }\end{array}$ & $\begin{array}{l}\text { Derived from the } \\
\text { P75 reference } \\
\text { profile }\end{array}$ \\
\hline$C_{\text {av }}[\mathrm{IU} / \mathrm{mL}]$ & 20 & 15 & 22 \\
$C_{\min }[\mathrm{IU} / \mathrm{mL}]$ & 16 & 11 & 16 \\
$C_{\max }[\mathrm{IU} / \mathrm{mL}]$ & 32 & 26 & 36 \\
\hline
\end{tabular}

Estimates are presented for doses of $0.406 \mathrm{~g} / \mathrm{kg}$ body weight, (i.e., the median dose level of the reference dataset, assuming a potency of $216 \mathrm{IU}$ per $100 \mathrm{mg}$ intravenous or subcutaneous immunoglobulin [IVIG/SCIG])

protection from severe infection or even SARS-CoV-2 infection might be achieved.

While neutralizing plasma antibody levels remain to be validated as a correlate of protection in clinical studies, here we reported a rapid increase of SARS-CoV-2 neutralization potency in Octapharma's IVIG/SCIG final containers by means of ELISA and microneutralization testing against SARS-CoV-2 WT (D614G). We found a very good correlation of the ELISA data to the actual virus neutralization data, which is in line with previously published observations on the performance of the Euroimmun IgG ELISA, suggesting it to be a suitable surrogate to perform donation screening and even semi-quantitatively approximate SARS-CoV-2 neutralization potency in IVIG/ SCIG matrices [42-44].

The first positive IVIG/SCIG final containers were detected in December 2020, produced partly from
Fig. 3 Approximated time courses of the neutralizing antiSARS-CoV-2 IgG levels (IU/ $\mathrm{mL}$ ) throughout ten 4-weekly repeated doses of intravenous $\mathrm{IgG}$ (potency $216 \mathrm{IU} / 100 \mathrm{mg}$ ) dosed with the median dose of the reference dataset $(0.406 \mathrm{~g} /$ $\mathrm{kg}-\mathrm{BW})$. Data was processed using PCModfit v7.0 (2021). PK data was obtained from a previously published study [34]. $B W$ body weight, $P K$ pharmacokinetics

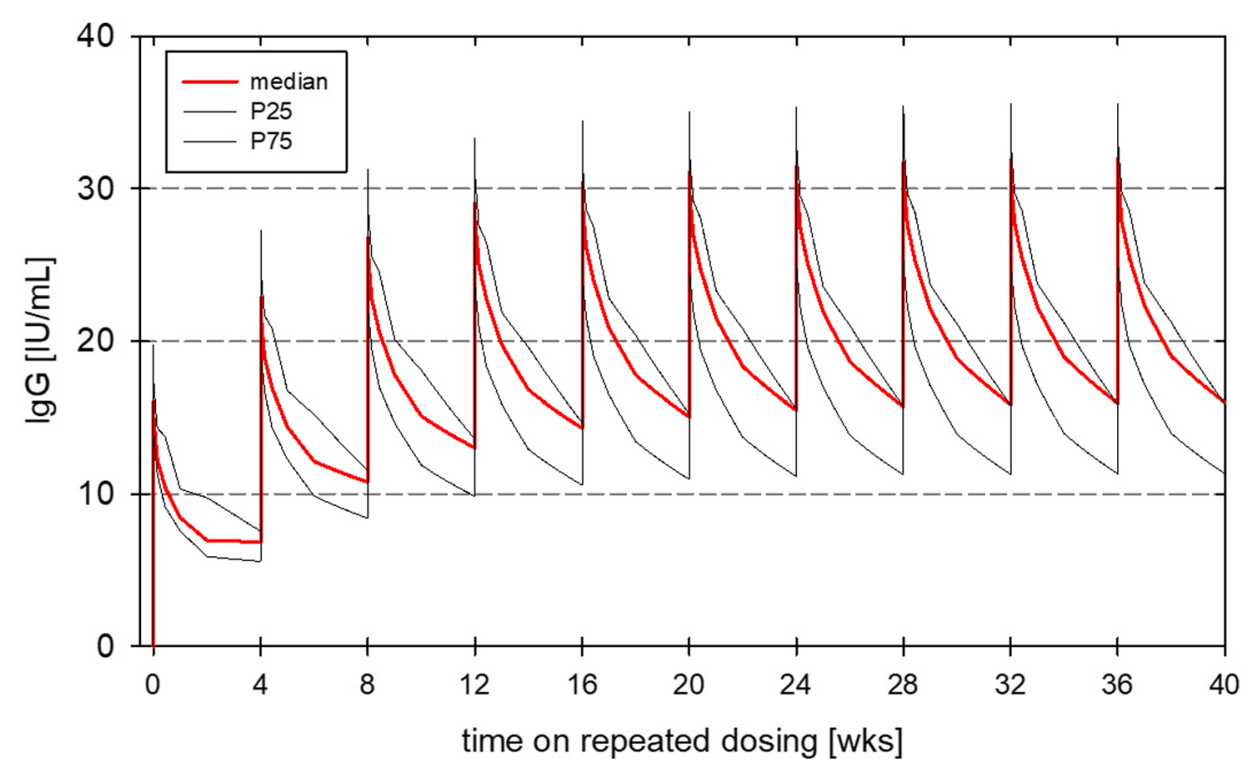


pre-pandemic plasma and donations obtained in August 2020 (minimum production lead time: 5 months). In contrast to a previous report, we could not detect a relevant cross-neutralizing activity in pre-pandemic batches of IVIG/SCIG [45]. The reported COVID-19 prevalence in July 2020 was about $1 \%$ [40], while recent reports suggest a 4.8-fold higher seroprevalence during the first wave of the pandemic [46]. In fact, a recent serological survey among US blood donors showed a $3.5 \%$ seroprevalence in July 2020 [47].

The observed increase in IVIG/SCIG final container neutralization titers from February 2021 to May 2021 (i.e., 61-216 IU/mL on average), fits well to the forecast by Farcet et al., who predicted $53-164 \mathrm{IU} / \mathrm{mL}$ for the same period of time [30]. Not factored into this prediction was the successful initial onset of the vaccination campaign in the US. The latter, which had an almost exponential increase with regards to 'first-dose in' in the total US population from January 2021 until May 2021, is potentially being responsible for the ongoing exponential increase in June 2021 [40]. This was also reported among blood donors where, with the onset of vaccinations in December 2020, an exponential increase was seen in overall seroprevalence to $>80 \%$ in May 2021, whilst infection-induced seroprevalence plateaued at that time [47].

Given that production of Octapharma's IVIG/SCIG takes at least 5 months from donation until filling, and with the reported exponential increase in serologically relevant exposure of the US total population from the first half-year in 2021 (inferring this to be an acceptable correlate of our donor population), a further increase of neutralization capacities at least until fall 2021 is suggested, while the exponential increase will likely see an inflection point and turn into a saturation phase. At which level SARS-CoV-2 neutralization titers will plateau and how stable this plateau will be over time depends on many factors, such as the following:

(i) The increase in vaccinees over-taking the $\mathrm{CP}$ donors in numbers might potentially lead to a different 'on-average', potentially more consistent contribution per plasma donation [48-50]. Our assessment of a small subset of convalescent donors $(n=313)$ showed that there was a marked spread in reactivity across the donations. Almost half of convalescent donations was non- or low reactive. This was more pronounced than in earlier reports, with almost a quarter of all donors as low/non-responders [51]. In our analysis, only about $10 \%$ of the investigated convalescent single donations could meet actual titer demands under revised emergency use authorization (EUA) issued by the FDA for CP treatment in acute COVID-19 infection [5]. However, these rare high-antibody titer donations eventually drive the titer in plasma pools.

(ii) Furthermore, first case reports have been described where convalescent patients received vaccinations with mRNA vaccines, boosting their neutralization titers at least
20 times their previous levels $[52,53]$. These booster effects will likely impact potencies in individual plasma donations and subsequently in the IVIG/SCIG final containers.

(iii) Even more interesting will be to see on which level anti-SARS-CoV-2 antibodies prevail in the long run, given waning of neutralization titers [54] and loss of sterile immunity on the mucosal surface of donors potentially allowing mild natural SARS-CoV-2 re-infection [55] and subsequent 'natural' titer boosts. A model for this could be the detectable levels of seasonal coronaviruses in IVIG/SCIG formulations [30, 56]. Additionally, depending on public health policies, repeated booster vaccinations may also drive long-term antibody levels against SARS-CoV-2 [57].

(iv) Leaving aside the insecurity regarding the quality of individual donations, we must emphasize that the manufacture of IVIG/SCIG also involves the pooling of intermediates and donations over a collection time span of up to one year, which has the potential to average out epidemiologic trends, such as vaccination levels.

While final container neutralization potencies against SARS-CoV-2 (D614G) are strongly increasing, it is of interest how these could translate into anti-SARS-CoV-2 IgG steady-state trough levels in a patient, which is one possible, yet not validated, correlate of immune protection. Approximations of the steady-state trough levels based on a 4-weekly IVIG administration by superposition of the median baseline-adjusted reference curve (derived from actual trial data [34]) indicate that doses of $0.4 \mathrm{~g} / \mathrm{kg}$ yield a trough level of about $7.4 \mathrm{mg} / \mathrm{mL}$ IgG. These superpositioned values correspond well to previously published IVIG steady state plasma levels [58].

As a basis for our calculation, the median anti-SARSCoV-2 neutralizing potency of $10 \%$ IVIG in May 2021 was chosen with $216 \mathrm{IU} / \mathrm{mL}$ or $216 \mathrm{IU} / 100 \mathrm{mg}=2.16 \mathrm{IU} / \mathrm{mg}$; rounded $2 \mathrm{IU} / \mathrm{mg}$. The approximated trough levels would correspondingly be about $16 \mathrm{IU} / \mathrm{mL}$ (P25: $11 \mathrm{IU} / \mathrm{mL}$, and P75: $16 \mathrm{IU} / \mathrm{mL}$ ) - provided there are no underlying idiotypespecific elimination processes. The variation found between pharmacokinetic profiles is in our opinion less important than an actual antibody plasma trough level (Table 1), such as the actual SARS-CoV-2 neutralization titer in the final container for which we have observed a substantial variation as can be seen in Fig. 2b. Likewise, the spans between the investigated time periods have more impact on the theoretical plasma trough levels than variation within pharmacokinetic reference profiles in [34]; a final container with the maximum neutralization potency measured (June 2021: $864 \mathrm{IU} / \mathrm{mL}$ ) would result in $64 \mathrm{IU} / \mathrm{mL}$ plasma trough levels, while the average final container potency in February 2021 $(61 \mathrm{IU} / \mathrm{mL})$ would lead to a $5-\mathrm{IU} / \mathrm{mL}$ plasma trough level.

To put these potential plasmatic NC50 values into context, Khoury et al. have recently published meta-analyses providing a first estimate of a protective level against 
detectable SARS-CoV-2 infection. They estimated a 50\% protection level from symptomatic SARS-CoV-2 infection to be around $20 \%$ of the CP titer ( $54 \mathrm{IU} / \mathrm{mL} ; 95 \%$ CI 30-96 $\mathrm{IU} / \mathrm{mL}$ ) [50]. Since effects of cellular immunity induced by vaccination might confound this suggested protective measure - and patients receiving IVIG/SCIG treatment are immunologically naïve or lack a potent cellular immunity especially for full protection, the protective threshold could be much higher. Also, it has to be kept in mind that neutralizing plasma antibodies have so far not been validated as a correlate of protection. In this light, the calculated antiSARS-CoV-2 antibody trough plasma levels (based on the average final container potency from 05/2021: $16 \mathrm{IU} / \mathrm{mL}$ ) are interpreted as sub-protective levels against infection (96 IU/mL; upper 95\% CI limit).

Although the epidemiological comparison to the US total population [40] is a sub-optimal-yet easily available—indicator of vaccination and COVID-19 convalescence for the actual donor population [47] and given what we observe in individual IVIG lots, an increase in anti-SARS-CoV-2 antibody titer to meet trough levels suggested by Khoury et al. seems possible. The current maximum NC50 value measured in IVIG/SCIG was $864 \mathrm{IU} / \mathrm{mL}$ in June 2021 and most seroconversions have occurred only recently (keeping in mind the $>5$-month lead time of IVIG/SCIG production). As discussed earlier, vaccination of convalescent donors also has been described to boost immunity, rendering individual plasma contributions potentially higher in titer than early in the pandemic [52, 53]. However, production of IVIG/SCIG involves intermediate production and pooling, which offers the potential to average plasma donation periods and hence not strictly follow donors' epidemiology.

While it is prudent to speculate on the ongoing increase of titers in IVIG/SCIG final containers, the long-term perspective of anti-SARS-CoV-2 antibody levels in IVIG/SCIG remains elusive and is surely impacted by, for example, longterm (sterile) immunity of the individual, public health policies (booster immunizations), and circulating SARS-CoV-2 variants. Furthermore, the required anti-SARS-CoV-2 titer in IVIG/SCIG has to be carefully interpreted as many uncertainties could play a role, such as (i) antibody levels without the back-up of cellular immunity have so far not been shown as a correlate of protection in immunocompromised patients. There are initial data that antibodies can protect against infection following recombinant monoclonal therapy in this group of patients [17]. (ii) The actual pharmacokinetics of anti-SARS-CoV-2 antibodies may differ from onaverage IVIG pharmacokinetic profiles, resulting in different plasma trough levels. Here, clinical studies in IVIG/SCIGreceiving patient cohorts are needed to provide information on plasma IgG levels in these patients and correlate these with the potencies found in the infused formulations. A further limitation is that the data presented here were generated using the D614G variant close to Wuhan wildtype strain, while the pandemic is currently driven by SARS-CoV-2 variants of concern and interest. Nevertheless, polyclonality of IVIG/SCIG could render a complete neutralization evasion of variants less likely as compared with monoclonal therapies. However, for polyclonal CP (from one donor) immune escape of variants of concern from neutralization has been shown with approximately 15 times lower neutralization titers, underscoring the general notion that optimal neutralization/protection is achieved against the isolate that caused the immune response [59]. In a passive immunization setting with IVIG/SCIG, this means not only trailing the epidemiology of donors in terms of neutralizing titer but also in terms of quality, meaning which variants will be neutralized best.

\section{Conclusion}

Here, we report the onset of SARS-CoV-2 neutralizing antibodies in IVIG/SCIG final containers from December 2020 with an exponential increase in neutralizing titers. The average values \pm SD found were February 2021: $61 \pm 37$ IU/ $\mathrm{mL}$; April 2021: $107 \pm 32 \mathrm{IU} / \mathrm{mL}$; May 2021: $216 \pm 96 \mathrm{IU} /$ $\mathrm{mL}$, and June 2021: $506 \pm 242 \mathrm{IU} / \mathrm{mL}$. The maximum NC50 measured so far was $864 \mathrm{IU} / \mathrm{mL}$.

Furthermore, we arbitrarily chose a recent, yet average, final container concentration to convert neutralization potencies of IVIG/SCIG final containers to possible troughplasma levels in steady-state. Trough-levels of $16 \mathrm{IU} / \mathrm{mL}$ were projected based on the average neutralizing titer in May 2021. While this value seems low, the highest detected final container potency of $864 \mathrm{IU} / \mathrm{mL}$ (maximum in the latest June 2021 time-point) would result in a theoretical trough level of $64 \mathrm{IU} / \mathrm{mL}$.

However, which plasma levels would be needed for protection against SARS-CoV-2 infection of immune-compromised patients is currently under discussion. A first estimate postulates $30-96 \mathrm{IU} / \mathrm{mL}$ with several caveats and limitations. It is therefore a matter of further clinical investigation to verify and pinpoint a protective antibody level in immunocompromised patients-without (or with reduced) background of cellular immunity.

Despite considerable lot-to-lot variability, a further increase based on the epidemiologic developments in the US plasma donor population seems plausible, at least until Fall 2021.

Supplementary Information The online version contains supplementary material available at https://doi.org/10.1007/s40259-021-00511-9.

Acknowledgements The authors cordially thank Prof. Dr Christian Drosten, Charité Berlin, Germany, for the provision of virus isolate Human 2019-nCoV ex China_BavPat1/2020_Germany ex China. 
Special thanks go to Gabriele Hoch and Lisa Oberland for virus and cell culture as well as the staff of Virus and Prion Validation at Octapharma for provision of expertise and support. The authors cordially thank Sonja Hoeller and Bernhard Rohrbacher (Global Medical and Scientific Affairs, Octapharma Pharmazeutika Produktionsgesellschaft m.b.H, Austria) for their input and critically reviewing the manuscript. We thank Monica Byrd (Octapharma Plasma Inc., USA), Sabine Simlinger, and Michael Szkutta (Octapharma Pharmazeutika Produktionsgesellschaft m.b.H Austria) for the provision of plasma donations as well as anonymized information on non-personal records and data. We thank the CoVIg Alliance for collaboration and exchange.

\section{Declarations}

Funding Octapharma Pharmazeutika Produktionsgesellschaft m.b.H., Austria and Octapharma Biopharmaceuticals GmbH, Germany, and Octapharma Plasma Inc., USA were the funding source. Octapharma Plasma Inc. was involved in plasma donation collection. Octapharma Pharmazeutika Produktionsgesellschaft m.b.H. and Octapharma Biopharmaceuticals $\mathrm{GmbH}$ were involved in analysis and data generation. Octapharma Pharmazeutika Produktionsgesellschaft m.b.H. covered all costs incurred for the present publication. ACPS-Network GmbH was paid for their pharmacokinetic analysis services by Octapharma Biopharmaceuticals GmbH.

Conflicts of interest AV, CCS, DK, JR, and TS are employed by companies that are part of the Octapharma group. CDM is owner and CEO of ACPS and received payment by Octapharma for the services involved in the preparation of this study.

Trademarks Octagam ${ }^{\circledR}$, Cutaquig ${ }^{\circledR}$ and Panzyga ${ }^{\circledR}$ are trademarks of the Octapharma group.

Availability of data and material Material that is still in existence and owned by Octapharma can be made available in principle for research purposes by non-profit organizations upon justified request. WHO International Standard was obtained from NIBSC, Potters Bar, UK (see materials and methods section) [36]. All data except epidemiologic data on seroconversion generated or analyzed during this study are included in this published article and its supplementary information files. Epidemiologic data on United States status of vaccination and COVID-19 cumulated cases were obtained from the CDC Data Tracker website [40].

Code availability Not applicable.

Ethics approval Not applicable.

Consent to participate All plasma donations analyzed in this study were obtained after informed consent of the donors. Plasma products analyzed within this study were produced from material donated after informed consent for the purpose of producing pharmaceutical products.

Consent to publish Not applicable.

Author contributions All authors contributed to the study conception and design. Material preparation, data collection, and analysis were performed by Andreas Volk, Caroline Covini-Souris, Christian de Mey, and Denis Kuehnel. The first draft of the manuscript was written by Andreas Volk and all authors commented on subsequent versions of the manuscript. All authors read and approved the final manuscript.
Open Access This article is licensed under a Creative Commons Attribution-NonCommercial 4.0 International License, which permits any non-commercial use, sharing, adaptation, distribution and reproduction in any medium or format, as long as you give appropriate credit to the original author(s) and the source, provide a link to the Creative Commons licence, and indicate if changes were made. The images or other third party material in this article are included in the article's Creative Commons licence, unless indicated otherwise in a credit line to the material. If material is not included in the article's Creative Commons licence and your intended use is not permitted by statutory regulation or exceeds the permitted use, you will need to obtain permission directly from the copyright holder. To view a copy of this licence, visit $\mathrm{http} / / /$ creativecommons.org/licenses/by-nc/4.0/.

\section{References}

1. Nobel Media AB 2021. The Nobel Prize in Physiology or Medicine 1901. 1901. https://www.nobelprize.org/prizes/medicine/ 1901/summary/. Accessed 6 Jun 2021.

2. Brown BL, McCullough J. Treatment for emerging viruses: convalescent plasma and COVID-19. Transfus Apher Sci. 2020;59: 102790. https://doi.org/10.1016/j.transci.2020.102790.

3. Focosi D, Tuccori M, Franchini M. The road towards polyclonal anti-SARS-CoV-2 immunoglobulins (Hyperimmune Serum) for passive immunization in COVID-19. Life (Basel). 2021. https:// doi.org/10.3390/life11020144.

4. Chen L, Xiong J, Bao L, Shi Y. Convalescent plasma as a potential therapy for COVID-19. Lancet Infect Dis. 2020;20:398-400. https://doi.org/10.1016/S1473-3099(20)30141-9.

5. Food and Drug Administration. Emergency Use Authorization of Covid-19 convalescent plasma.

6. Peng HT, Rhind SG, Beckett A. convalescent plasma for the prevention and treatment of COVID-19: a systematic review and quantitative analysis. JMIR Public Health Surveill. 2021;7: e25500. https://doi.org/10.2196/25500.

7. Franchini M, Glingani C, Morandi M, Corghi G, Cerzosimo S, Beduzzi G, et al. Safety and efficacy of convalescent plasma in Elderly COVID-19 patients: the RESCUE trial. Mayo Clin Proc Innov Qual Outcomes. 2021;5:403-12. https://doi.org/10.1016/j. mayocpiqo.2021.01.010.

8. Gharbharan A, Jordans CCE, GeurtsvanKessel C, den Hollander JG, Karim F, Mollema FPN, et al. Effects of potent neutralizing antibodies from convalescent plasma in patients hospitalized for severe SARS-CoV-2 infection. Nat Commun. 2021;12:3189. https://doi.org/10.1080/01621459.1999.10474144.

9. Klassen SA, Senefeld JW, Johnson PW, Carter RE, Wiggins CC, Shoham S, et al. The effect of convalescent plasma therapy on mortality among patients with COVID-19: systematic review and meta-analysis. Mayo Clin Proc. 2021;96:1262-75. https://doi.org/ 10.1016/j.mayocp.2021.02.008.

10. Joyner MJ, Carter RE, Senefeld JW, Klassen SA, Mills JR, Johnson PW, et al. Convalescent plasma antibody levels and the risk of death from covid-19. N Engl J Med. 2021;384:1015-27. https:// doi.org/10.1056/NEJMoa2031893.

11. Libster R, Pérez Marc G, Wappner D, Coviello S, Bianchi A, Braem V, et al. Early high-titer plasma therapy to prevent severe Covid-19 in older adults. N Engl J Med. 2021;384:610-8. https:// doi.org/10.1056/NEJMoa2033700.

12. Simonovich VA, Burgos Pratx LD, Scibona P, Beruto MV, Vallone MG, Vázquez C, et al. A randomized trial of convalescent plasma in Covid-19 severe pneumonia. N Engl J Med. 2021;384:619-29. https://doi.org/10.1056/NEJMoa2031304.

13. Haagmans BL, Noack D, Okba NMA, Li W, Wang C, Bestebroer $\mathrm{T}$, et al. SARS-CoV-2 neutralizing human antibodies protect 
against lower respiratory tract disease in a hamster model. J Infect Dis. 2020;223:2020-8. https://doi.org/10.1101/2020.08. 24.264630 .

14. Chen RE, Winkler ES, Case JB, Aziati ID, Bricker TL, Joshi A, et al. In vivo monoclonal antibody efficacy against SARSCoV-2 variant strains. Nature. 2021. https://doi.org/10.1038/ s41586-021-03720-y.

15. McMahan K, Yu J, Mercado NB, Loos C, Tostanoski LH, Chandrashekar A, et al. Correlates of protection against SARS-CoV-2 in rhesus macaques. Nature. 2021;590:630-4. https://doi.org/10. 1038/s41586-020-2456-9.

16. Cohen MS, Nirula A, Mulligan MJ, Novak RM, Marovich M, Yen $\mathrm{C}$, et al. Effect of bamlanivimab vs placebo on incidence of COVID-19 among residents and staff of skilled nursing and assisted living facilities: a randomized clinical trial. JAMA. 2021. https://doi.org/10.1001/jama.2021.8828.

17. Alexandra Bowie. Regeneron Reports Positive Interim Data with REGEN-COVTM Antibody Cocktail used as Passive Vaccine to Prevent COVID-19. TARRYTOWN, N.Y., USA; January 26, 2021.

18. Hagin D, Freund T, Navon M, Halperin T, Adir D, Marom R, et al. Immunogenicity of Pfizer-BioNTech COVID-19 vaccine in patients with inborn errors of immunity. J Allergy Clin Immunol. 2021. https://doi.org/10.1016/j.jaci.2021.05.029.

19. Kinoshita H, Durkee-Shock J, Jensen-Wachspress M, Kankate VV, Lang $\mathrm{H}$, Lazarski CA, et al. Robust antibody and $\mathrm{T}$ cell responses to SARS-CoV-2 in patients with antibody deficiency. J Clin Immunol. 2021. https://doi.org/10.1007/s10875-021-01046-y.

20. Tougeron D, Hentzien M, Seitz-Polski B, Bani-Sadr F, Bourhis J, Ducreux M, et al. Severe acute respiratory syndrome coronavirus 2 vaccination for patients with solid cancer: review and point of view of a French oncology intergroup (GCO, TNCD, UNICANCER). Eur J Cancer. 2021;150:232-9. https://doi.org/10.1016/j. ejca.2021.03.030

21. Durandy A, Kracker S, Fischer A. Primary antibody deficiencies. Nat Rev Immunol. 2013;13:519-33. https://doi.org/10.1038/nri34 66.

22. Meyts I, Bucciol G, Quinti I, Neven B, Fischer A, Seoane E, et al. Coronavirus disease 2019 in patients with inborn errors of immunity: an international study. J Allergy Clin Immunol. 2021;147:520-31. https://doi.org/10.1016/j.jaci.2020.09.010.

23. Delavari S, Abolhassani H, Abolnezhadian F, Babaha F, Iranparast S, Ahanchian $\mathrm{H}$, et al. Impact of SARS-CoV-2 pandemic on patients with primary immunodeficiency. J Clin Immunol. 2021;41:345-55. https://doi.org/10.1007/s10875-020-00928-x.

24. Dwyer JM. Immunoglobulins in autoimmunity: history and mechanisms of action. Clin Exp Rheumatol. 1996;14(Suppl 15):S3-7.

25. Ramesh S, Schwartz SA. Therapeutic uses of intravenous immunoglobulin (IVIG) in children. Pediatr Rev. 1995;16:403-10 (quiz 410).

26. Stiehm ER. Human intravenous immunoglobulin in primary and secondary antibody deficiencies. Pediatr Infect Dis J. 1997;16:696-707. https://doi.org/10.1097/00006454-19970 7000-00012.

27. Radomski KU, Lattner G, Schmidt T, Römisch J. Pathogen safety of a new intravenous immune globulin $10 \%$ liquid. BioDrugs. 2017;31:125-34. https://doi.org/10.1007/s40259-017-0212-y.

28. Frenzel W, Wietek S, Svae T-E, Debes A, Svorc D. Tolerability and safety of Octagam ${ }^{\circledR}$ (IVIG): a post-authorization safety analysis of four non-interventional phase IV trials. Int J Clin Pharmacol Ther. 2016;54:847-55. https://doi.org/10.5414/CP202782.

29. Karbiener M, Farcet MR, Ilk R, Schreiner J, Lenart J, Powers $\mathrm{N}$, et al. Longitudinal analysis of SARS-CoV-2 antibodies in 8000 U.S. first-time convalescent plasma donations. Transfusion. 2021;61:1141-7. https://doi.org/10.1111/trf.16291.
30. Farcet MR, Karbiener M, Schwaiger J, Ilk R, Kreil TR. Rapidly increasing SARS-CoV-2 neutralization by intravenous immunoglobulins produced from plasma collected during the 2020 pandemic. J Infect Dis. 2020. https://doi.org/10.1093/infdis/jiab142.

31. Pisani G, Cristiano K, Simeoni M, Martina A, Pati I, Carocci A, et al. Detection of antibodies against SARS-CoV-2 both in plasma pools for fractionation and in commercial intravenous immunoglobulins produced from plasma collected in Italy during the pandemic. Blood Transfus. 2021. https://doi.org/10.2450/ 2021.0055-21.

32. Vandeberg P, Cruz M, Diez JM, Merritt WK, Santos B, Trukawinski S, et al. Brief report: production of anti-SARS-CoV-2 hyperimmune globulin from convalescent plasma. Transfusion. 2021. https://doi.org/10.1111/trf.16378.

33. Ali S, Uddin SM, Ali A, Anjum F, Ali R, Shalim E, et al. Production of hyperimmune anti-SARS-CoV-2 intravenous immunoglobulin from pooled COVID-19 convalescent plasma. Immunotherapy. 2021;13:397-407. https://doi.org/10.2217/imt-2020-0263.

34. Melamed IR, Borte M, Trawnicek L, Kobayashi A-L, Kobayashi $\mathrm{RH}$, Knutsen A, et al. Pharmacokinetics of a novel human intravenous immunoglobulin $10 \%$ in patients with primary immunodeficiency diseases: Analysis of a phase III, multicentre, prospective, open-label study. Eur J Pharm Sci. 2018;118:80-6. https://doi.org/ 10.1016/j.ejps.2018.03.007.

35. Wölfel R, Corman VM, Guggemos W, Seilmaier M, Zange S, Müller MA, et al. Virological assessment of hospitalized patients with COVID-2019. Nature. 2020;581:465-9. https://doi.org/10. 1016/S1473-3099(15)70090-3.

36. Kristiansen PA, Page M, Bernasconi V, Mattiuzzo G, Dull P, Makar K, et al. WHO International Standard for anti-SARSCoV-2 immunoglobulin. Lancet. 2021;397:1347-8. https://doi. org/10.1016/S0140-6736(21)00527-4.

37. Gauger PC, Vincent AL. Serum virus neutralization assay for detection and quantitation of serum-neutralizing antibodies to influenza A virus in swine. Methods Mol Biol. 2014;1161:31324. https://doi.org/10.1007/978-1-4939-0758-8_26.

38. Orlinger KK, Holzer GW, Schwaiger J, Mayrhofer J, Schmid $\mathrm{K}$, Kistner $\mathrm{O}$, et al. An inactivated West Nile Virus vaccine derived from a chemically synthesized cDNA system. Vaccine. 2010;28:3318-24. https://doi.org/10.1016/j.vaccine.2010.02.092.

39. Cavalli-Sforza L. Grundzüge biologische-medizinischer Statistik. 3rd ed. Stuttgart: Gustav Fischer Verlag; 1972.

40. Centers for Disease Control and Prevention. CDC Covid Data Tracker. 2021. https://covid.cdc.gov/covid-data-tracker/\#nationallab. Accessed 2 Jun 2021.

41. United States Census Bureau. U.S. and World Population Clock. https://www.census.gov/popclock/. Accessed 2 Jun 2021.

42. Walker GJ, Naing Z, Ospina Stella A, Yeang M, Caguicla J, Ramachandran V, et al. SARS Coronavirus-2 microneutralisation and commercial serological assays correlated closely for some but not all enzyme immunoassays. Viruses. 2021. https://doi.org/10. 3390/v13020247.

43. Rychert J, Couturier MR, Elgort M, Lozier BK, La'ulu S, Genzen JR, et al. Evaluation of 3 SARS-CoV-2 IgG antibody assays and correlation with neutralizing antibodies. J Appl Lab Med. 2021;6:614-24. https://doi.org/10.1093/jalm/jfaa188.

44. Jääskeläinen AJ, Kuivanen S, Kekäläinen E, Ahava MJ, Loginov R, Kallio-Kokko H, et al. Performance of six SARS-CoV-2 immunoassays in comparison with microneutralisation. J Clin Virol. 2020;129: 104512. https://doi.org/10.1016/j.jcv.2020.104512.

45. Díez J-M, Romero C, Vergara-Alert J, Belló-Perez M, Rodon J, Honrubia JM, et al. Cross-neutralization activity against SARSCoV-2 is present in currently available intravenous immunoglobulins. Immunotherapy. 2020;12:1247-55. https://doi.org/10.2217/ imt-2020-0220. 
46. Kalish H, Klumpp-Thomas C, Hunsberger S, Baus HA, Fay MP, Siripong N, et al. Undiagnosed SARS-CoV-2 seropositivity during the first 6 months of the COVID-19 pandemic in the United States. Sci Transl Med. 2021. https://doi.org/10.1126/scitranslm ed.abh3826.

47. Jones JM, Stone M, Sulaeman H, Fink RV, Dave H, Levy ME, et al. Estimated US infection- and vaccine-induced SARS-CoV-2 seroprevalence based on blood donations, July 2020-May 2021. JAMA. 2021. https://doi.org/10.1001/jama.2021.15161.

48. Jackson LA, Anderson EJ, Rouphael NG, Roberts PC, Makhene $\mathrm{M}$, Coler RN, et al. An mRNA vaccine against SARS-CoV-2Preliminary report. N Engl J Med. 2020;383:1920-31. https://doi. org/10.1056/NEJMoa2022483.

49. Polack FP, Thomas SJ, Kitchin N, Absalon J, Gurtman A, Lockhart S, et al. Safety and efficacy of the BNT162b2 mRNA Covid19 vaccine. N Engl J Med. 2020;383:2603-15. https://doi.org/10. 1056/NEJMoa2034577.

50. Khoury DS, Cromer D, Reynaldi A, Schlub TE, Wheatley AK, Juno JA, et al. Neutralizing antibody levels are highly predictive of immune protection from symptomatic SARS-CoV-2 infection. Nat Med. 2021. https://doi.org/10.1198/jcgs.2009.07130.

51. Li L, Tong X, Chen H, He R, Lv Q, Yang R, et al. Characteristics and serological patterns of COVID-19 convalescent plasma donors: optimal donors and timing of donation. Transfusion. 2020. https://doi.org/10.1111/trf.15918.

52. Vickers MA, Sariol A, Leon J, Ehlers A, Locher AV, Dubay KA, et al. Exponential increase in neutralizing and spike specific antibodies following vaccination of COVID-19 convalescent plasma donors. Transfusion. 2021. https://doi.org/10.1111/trf.16401.

53. Stamatatos L, Czartoski J, Wan Y-H, Homad LJ, Rubin V, Glantz $\mathrm{H}$, et al. mRNA vaccination boosts cross-variant neutralizing antibodies elicited by SARS-CoV-2 infection. Science. 2021. https://doi.org/10.1126/science.abg9175.

54. Marot S, Malet I, Leducq V, Zafilaza K, Sterlin D, Planas D, et al. Rapid decline of neutralizing antibodies against SARS-CoV-2 among infected healthcare workers. Nat Commun. 2021;12:844. https://doi.org/10.1038/s41467-021-21111-9.

55. Sterlin D, Mathian A, Miyara M, Mohr A, Anna F, Claër L, et al. IgA dominates the early neutralizing antibody response to SARSCoV-2. Sci Transl Med. 2021. https://doi.org/10.1126/scitranslm ed.abd2223.

56. Díez JM, Romero C, Gajardo R. Effective presence of antibodies against common human coronavirus in $\mathrm{IgG}$ immunoglobulin medicinal products. online: bioRxiv; 2021. https://doi.org/10. 1101/2021.07.23.453571.

57. Kai Wu, Angela Choi, Matthew Koch, LingZhi Ma, Anna Hill, Naveen Nunna, Wenmei Huang, Judy Oestreicher, Tonya Colpitts, Hamilton Bennett, Holly Legault, Yamuna Paila, Biliana Nestorova, Baoyu Ding, Rolando Pajon, Jacqueline M Miller, Brett Leav, Andrea Carfi, Roderick McPhee, Darin K Edwards. Preliminary Analysis of Safety and Immunogenicity of a SARSCoV-2 Variant Vaccine Booster. medRxiv. 2021: Preprint. https:// doi.org/10.1101/2021.05.05.21256716.

58. Bonilla FA. Pharmacokinetics of immunoglobulin administered via intravenous or subcutaneous routes. Immunol Allergy Clin N Am. 2008;28(803-19):ix. https://doi.org/10.1016/j.iac.2008.06. 006.

59. Cele S, Gazy I, Jackson L, Hwa S-H, Tegally H, Lustig G, et al. Escape of SARS-CoV-2 501Y.V2 from neutralization by convalescent plasma. Nature. 2021;593:142-6. https://doi.org/10.1016/j. xcrm.2021.100204.

\title{
Authors and Affiliations
}

\author{
Andreas Volk ${ }^{1} \cdot$ Caroline Covini-Souris $^{2} \cdot$ Denis Kuehnel ${ }^{1} \cdot$ Christian De Mey $^{3} \cdot$ Jürgen Römisch $^{2} \cdot$ Torben Schmidt $^{1}$ \\ Andreas Volk \\ andreas.volk@octapharma.com \\ $1 \quad$ Virus and Prion Validation, Octapharma Biopharmaceuticals \\ 2 R\&D Plasma, Octapharma Pharmazeutika \\ Produktionsgesellschaft m.b.H., Vienna, Austria \\ 3 ACPS-Network GmbH, Wiesbaden, Germany
} $\mathrm{GmbH}$, Frankfurt, Germany 